\title{
The Role of Surgery in Primary Thyroid Lymphoma: Experience in the Last 10 Years of a Specialized Unit
}

\author{
Raquel Alfonso-Ballester¹, María José Terol Castera², Omar García Rodríguez³, Carolina Martínez \\ Ciarpaglini $^{4}$, Marta Maia Boscá-Watts ${ }^{5}$, Norberto Cassinello Fernández¹, Joaquín Ortega Serrano ${ }^{1}$
}

\author{
${ }^{1}$ Departments of Surgery (Endocrine Section), University Clinic Hospital of Valencia, Valencia, Spain \\ ${ }^{2}$ Departments of Medical Oncology, University Clinic Hospital of Valencia, Valencia, Spain \\ ${ }^{3}$ Departments of Oral and Maxillofacial Surgery, University Clinic Hospital of Valencia, Valencia, Spain \\ ${ }^{4}$ Departments of Pathology, University Clinic Hospital of Valencia, Valencia, Spain \\ ${ }^{5}$ Departments of Digestive Medicine, University Clinic Hospital of Valencia, Valencia, Spain \\ Email: raquelalfonsoballester@msn.com
}

How to cite this paper: Alfonso-Ballester, R., Terol Castera, M.J., García Rodríguez, O., Martínez Ciarpaglini, C., Boscá-Watts, M.M., Cassinello Fernández, N. and Ortega Serrano, J. (2016) The Role of Surgery in Primary Thyroid Lymphoma: Experience in the Last 10 Years of a Specialized Unit. Journal of Cancer Therapy, 7, 1059-1070.

http://dx.doi.org/10.4236/jct.2016.713102

Received: November 14, 2016

Accepted: December 25, 2016

Published: December 28, 2016

Copyright $\odot 2016$ by authors and Scientific Research Publishing Inc. This work is licensed under the Creative Commons Attribution International License (CC BY 4.0).

http://creativecommons.org/licenses/by/4.0/

(c) $\underset{\mathrm{EY}}{\text { (i) Open Access }}$

\begin{abstract}
Primary Thyroid Lymphoma (PTL) is an uncommon disease, although its incidence is of 5\%. Ultrasound and Fine Needle Aspiration Cytology (FNAC) usually do not provide the diagnosis. Surgery is one of the treatment options because it enables histological diagnosis and can also relieve compression symptoms in patients with rapid growth cervical mass. We present 7 cases of PTL diagnosed in the last 10 years in our unit. Five were female (71.4\%) and 2 were male (28.6\%). The mean age was 64.2 (range: $40-81$ ); 4 patients (57.1\%) had associated Hashimoto's Thyroiditis (HT). One patient (14.2\%) had concomitant Graves disease. 5 cases presented with compressive symptoms and cervical mass. Ultrasound was not diagnostic in any case. FNAC was diagnostic only in one patient (14.3\%). Five patients underwent total thyroidectomy (71.4\%). All the cases were diagnosed with lymphoma postoperatively. Two interventions consisted of left hemithyroidectomies (28.6\%). No complications appeared. 5 patients (71.4\%) were classified as Mucosa-Associated Lymphoid Tissue (MALT) lymphoma. We also observed 1 Follicular grade I lymphoma and 1 Burkitt case. When the extension study was done, 1 patient was at stage IIIE (14\%), 2 at IIE (28.5\%) and 4 at IE (57.14\%). Rituximab, cyclophosphamide, doxorubicin, vincristine and prednisone (R-CHOP) and Iphosphamide, ethoposide and high dose Cytarabine (IVAC) were the treatment scheme when chemotherapy was used (in three cases). Two cases were treated only with total thyroidectomy, and 2 with total thyroidectomy and rituximab, and the latter was MALT. Complete Remission (CR) was achieved in all patients in the first year. All are still alive and in CR. In our experience, PTL diagnose can be challenging before surgery. Although surgery is not the
\end{abstract}


gold standard for treatment, when it is done, it should be curative in MALT lymphomas confined to the thyroid.

\section{Keywords}

Thyroid, Lymphoma, Thyroidectomy, Endocrine Surgery, Extranodal Lymphoma, Malt Lymphoma, Rituximab

\section{Introduction}

Primary Thyroid Lymphoma (PTL) is defined as a lymphoma arising in the thyroid gland. It accounts for only $5 \%$ of all thyroid malignancies [1], and represents $3 \%$ of all non-Hodgkin's lymphoma. The typical presentation is in middle-aged women with Hashimoto's thyroiditis (HT). It is extremely rare in the paediatric population [2].

The most common clinical presentation is a rapidly enlarging painless thyroid mass. Sometimes it may be associated with compressive symptoms such as dysphagia, dyspnea and hoarseness. B-symptoms are referred in $20 \%$ of cases [3].

Tumors are usually cerebroid and well vascularized. Ultrasonography is the imaging modality of choice and typically shows one of the three patterns: nodular, diffuse or mixed. When appearing as a solitary mass, the tumor may resemble an anaplastic thyroid carcinoma, but the lack of calcification, necrosis and cystic degeneration favors diagnosis as lymphoma.

T-cell PTL is extremely rare, accounting for only $2 \%$ [4] of the whole series while B-cell PTL represents up to $98 \%$. The most frequent histological subtypes were Diffuse Large B-Cell Lymphoma (DLBCL) and MALT lymphoma, accounting for up to $70 \%$ and $30 \%$, respectively. Other histological subtypes, such as follicular or Burkitt's lymphoma comprise only $3 \%-5 \%$ of PTL. DLBCL is the most aggressive subtype, with $50 \%-60 \%$ of patients presenting disseminated disease at diagnosis and poor prognosis. DLBCL can be also divided into two major cell-origin subtypes with different prognosis: a favourable germinal-centre B-cell-like lymphoma and a more aggressive activated B-cell-like subtype with overexpression of immunophenotype markers IRF4 (MUM1) and FOXP1. MALT lymphomas are characterized by the presence of lymphoepithelial lesions, representing colonization of the thyroid follicles by the lymphoma cells.

Staging is based on Modified Ann Arbor criteria [5]. Stage IE applies to disease confined within the thyroid; stage IIE represents thyroid and regional lymph node involvement; IIIE represents thyroid and lymph node involvement on both sides of the diaphragm and stage IV comprises disseminated disease. Diagnosis is based on histological analysis of thyroid tissue.

Although in the last few years ultrasound guided FNAC and core-biopsy have increased their sensitivity [6] [7], an open surgical biopsy is needed to allow accurate diagnosis of the different lymphoma subtypes in order to direct treatment.

Treatment strategy depends on histological subtype and stage. Due to the low incidence, there is no evidence-based treatment. DLBCL requires multimodal therapy, in- 
cluding immunochemotherapy and radiotherapy for bulky disease. Early stage IE MALT PTL has an indolent course and may call for single-modality treatment including surgery, radiotherapy or a combination of both.

Prognosis is generally excellent although dependent on histological subtype.

\section{Materials and Methods}

The PTL cases detected in the unit of Endocrine Surgery of the University Clinic Hospital of Valencia, Spain, in the last 10 years were reviewed and analyzed. It is a retrospective and descriptive study. Cases were obtained from Oncology, Pathology and Surgery database.

\section{Results}

1267 patients underwent thyroid surgery in our unit during the period from 2005 to 2015. From that, 7 cases were diagnosed with PTL (0.55\%). Five were female (71.4\%) and 2 were male (28.6\%). The mean age was 64.2 (range: 40 - 81); 4 patients (57.1\%) had associated HT. One patient (14.2\%) had concomitant Graves disease.

Five patients debuted as a cervical mass with compressive symptoms. Three of them developed as a rapidly growing cervical mass, one of which grew from 2 to $8 \mathrm{~cm}$ diameter (Figure 1 and Figure 2). In 2 of these patients PTL started with compressive symptoms. Two cases out of the total (28.6\%) showed no symptoms at all.

In all cases a cervical ultrasound was performed as an initial study. In no case did the ultrasound show evidence of thyroid lymphoma.

FNAC was diagnostic only in one patient (14.3\%).

Five patients underwent total thyroidectomy (71.4\%). All were diagnosed with lymphoma postoperatively. Two interventions consisted of left hemithyroidectomies (28.6\%). One was indicated preoperatively in order to relieve compressive symptoms and the other was called because the intraoperative biopsy informed of a lymphoma, which made the complete thyroidectomy unnecessary.

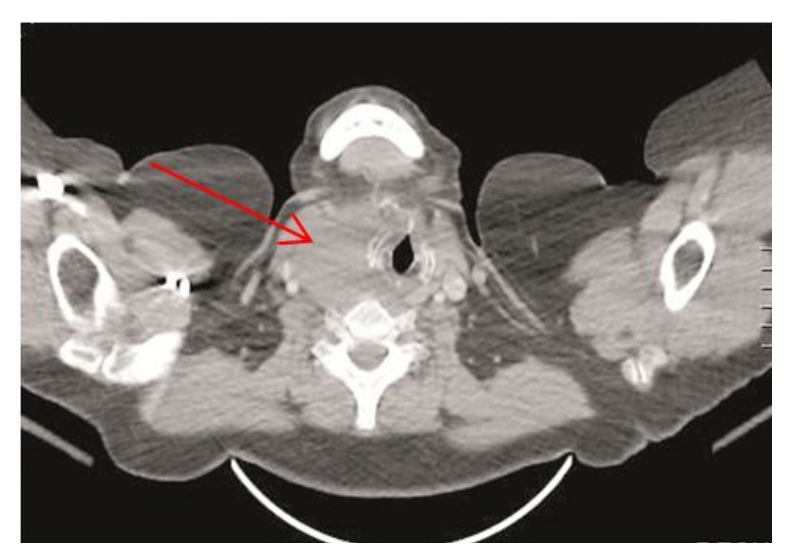

Figure 1. CT scan axial vision with oral gastrografin. A thyroid mass is identified, mainly in the right thyroid lobe causing severe tracheal deviation. The rapidly growing cervical mass is marked with a red arrow. 


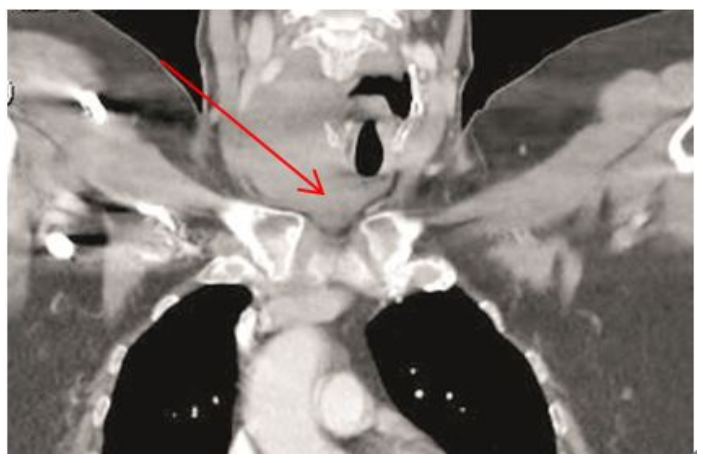

Figure 2. CT scan with oral gastrografin, coronal vision. The rapidly growing cervical mass is marked with a red arrow.

No postoperative complications appeared in any case.

Histological report was of MALT lymphoma in 5 patients (71.4\%). We also observed a Follicular grade I lymphoma and a Burkitt case (Figures 3-5).

The extension was evaluated in all patients with cervical and thoracic CT scan, Bone Marrow Biopsy (BMB), beta-2 microglobuline and serum lactate dehydrogenase (LDH) levels. BMB showed normal cellularity. Beta-2 microglobuline did not rise in any patient and LDH levels only increased in 1 of the 7 cases. One case (the Burkitt case) was staged as IIIE (14\%), 2 as IIE (28.5\%) and 4 as IE (57.14\%).

Three patients completed treatment with R-CHOP (Rituximab, Cyclophosphamide, Doxorubicin, Vincristine and Prednisone). The Burkitt lymphoma was treated with Dexamethasone, methotrexate and IVAC (iphosphamide ethoposide and cytarabine). Two cases were treated only with Total Thyroidectomy, and 2 with total thyroidectomy and Rituximab, the latter were MALT.

Complete remission (CR) was achieved in all patients in the first year. All are still alive and in CR (see results in Table 1).

\section{Discussion}

PTL has a very low incidence, with 1 - 2 cases per million. Due to this low frequency it is especially interesting to report case-series. Most published studies are retrospective with a limited number of patients. Series with a larger number of patients were presented by Matsuzuka $(\mathrm{n}=119)$ and Onal $(\mathrm{n}=87)$ [8] [9]. Incidence varied between $2 \%$ - $8 \%$, with female/male predominance of $4: 1$. PTL is extremely rare in paediatric population and is most commonly observed at middle-to-advanced age, between 60 and to 75 years old, with a female/male ratio of 4:1 [10]. Similarly, our patients presented a mean age of 64.2 and a similar female/male ratio (5:2).

The main clinical presentation included a mass in the thyroid or a diffuse enlargement that caused symptoms related to compression such as hoarseness, dysphagia and dyspnea. Rarely, stridor or superior vena cava obstruction may occur. There was a report of one case presenting a thyroid abscess which was in fact affected by Hodgkin's lymphoma [11]. Five patients in our series had a mass or a diffuse enlargement producing compressive symptoms. Two patients were asymptomatic. One of them did not 


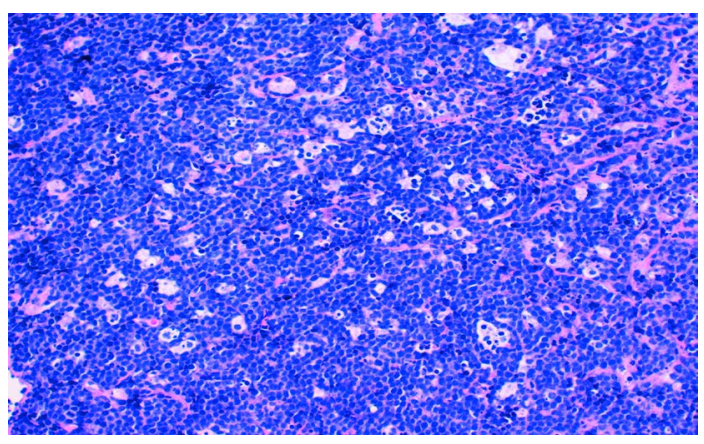

Figure 3. Burkitt lymphoma: Diffuse infiltration in a starry sky pattern, with medium size lymphocytes, homogeneous, with lax chromatine and some prominent nucleoli among which we can identify abundant tangible body macrophages.

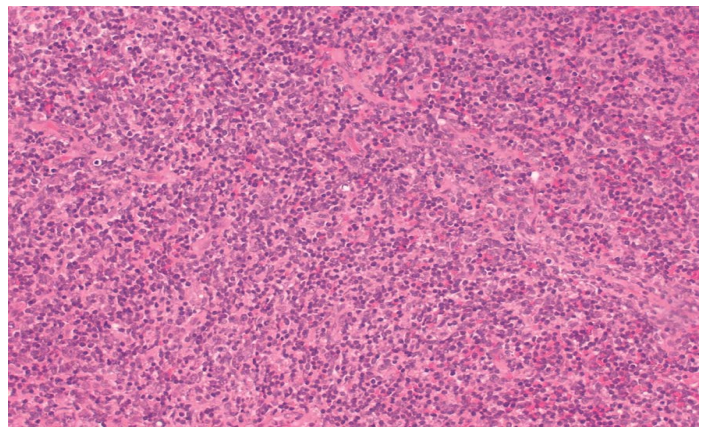

Figure 4. MALT lymphoma: Diffuse infiltration of small and medium size lymphocytes that completely erases normal architecture of the organ.

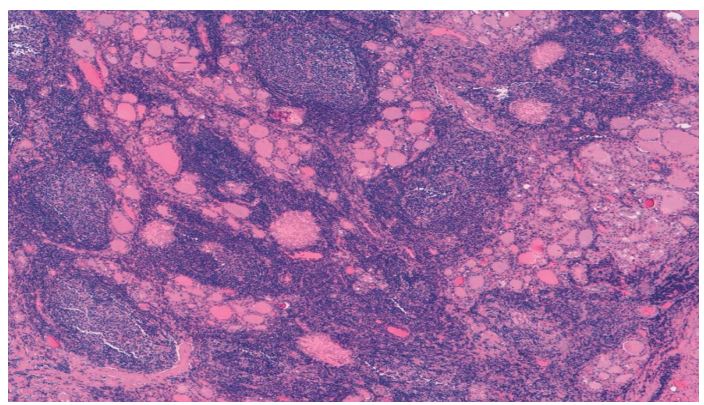

Figure 5. Follicular lymphoma: numerous lymphoid follicles with asymmetrical germinal centres, without tangible body macrophages.

show thyroid enlargement and surgical treatment indication was based on unmanageable hyperthyroidism with medical treatment. Classic B-symptoms such have been reported in up to $20 \%$ of patients. None of our patients referred B-symptoms.

The pathogenesis of PTL lymphoma is closely related to chronic antigen stimulation, and the major risk factor for MALT lymphomas is the presence of Hashimoto's thyroiditis (HT). The risk of PTL in an HT patient is increased 40 - 80 times compared to the general population [12] [13] and PTL typically develops 20 - 30 years after initial diagnosis. Although the incidence of HT in PTL patients is up to $80 \%$, only $0.6 \%$ with HT will develop a PTL [14]. Williams et al. reported a causal relationship between HT 
Table 1. Clinical aspects of the patients who underwent surgery during the last 10 years in our hospital.

\begin{tabular}{|c|c|c|c|c|c|c|c|}
\hline $\begin{array}{l}\text { CASE } \\
\text { (Year) }\end{array}$ & $\begin{array}{c}1 \\
2005\end{array}$ & $\begin{array}{c}2 \\
2006\end{array}$ & $\begin{array}{c}3 \\
2007\end{array}$ & $\begin{array}{c}4 \\
2008\end{array}$ & $\begin{array}{c}5 \\
2010\end{array}$ & $\begin{array}{c}6 \\
2013\end{array}$ & $\begin{array}{c}7 \\
2014\end{array}$ \\
\hline SEX & $\mathrm{F}$ & $\mathrm{F}$ & M & F & $\mathrm{F}$ & $\mathrm{F}$ & M \\
\hline THYROIDITIS & - & Graves & Hashimoto & Hashimoto & Hashimoto & - & Hashimoto \\
\hline FNAC DIAGNOSTIC & - & - & - & - & - & + & - \\
\hline HISTOLOGY & MALT & MALT & MALT & $=$ MALT & Folilcular grade I & Burkitt & MALT \\
\hline $\begin{array}{l}\text { CT STAGE } \\
\text { (RYE) }\end{array}$ & IIE & IE & IE & IIE & IE & IIIE & IE \\
\hline TREATMENT & $\begin{array}{c}\mathrm{TT}+\mathrm{CT} \\
(\mathrm{R}-\mathrm{CHOP})\end{array}$ & $\mathrm{TT}$ & $\mathrm{TT}$ & $\begin{array}{c}\text { TT + RITU } \\
\text { XIMAB }\end{array}$ & $\begin{array}{c}\text { Lobectomy + CT } \\
\quad(\mathrm{R}-\mathrm{CHOP})\end{array}$ & $\begin{array}{c}\text { Lobectomy + RITUXIMAB + } \\
\text { CORTICOID + } \\
\text { METOTREXATE }+ \\
\text { IVAC }\end{array}$ & $\begin{array}{c}\text { TT + } \\
\text { RITU } \\
\text { XIMAB }\end{array}$ \\
\hline $\begin{array}{l}\text { SURVIVAL } \\
\text { (YEARS) }\end{array}$ & 11 & 10 & 9 & 8 & 6 & 3 & 2 \\
\hline
\end{tabular}

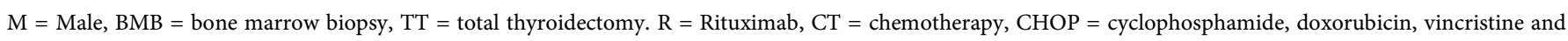
prednisone, IVAC (iphosphamide ethoposide and high dose cytarabine).

and PTL [15]. Another series reported a 67-fold increased risk of developing PTL among HT patients [16]. In our series, 4 patients out of 5 with indolent lymphoma had an HT diagnosis. Some patients present increased T4 levels and no detectable anti-peroxidase antibodies [17] [18]. This could be explained by tumoral infiltration of the gland, which destroys normal thyroid follicles leading to the release of thyroxine.

MALT lymphoma of the thyroid usually has an indolent course and a better prognosis but transformation into higher grade subtypes has been previously documented. Although the most frequent site of involvement is the gastrointestinal tract, it may also arise in other extranodal locations such as skin, breast, lung or thyroid. MALT PTL accounts for 5\% of all extranodal lymphomas [19] [20]. Cases associating MALT lymphoma with Papillar carcinoma have been reported, but this combination is extremely rare [21] [22]. Treating the papillar carcinoma was critical in those cases, with good results.

In our experience MALT lymphoma was more frequent than the other subtypes, with 5 out of 7 patients, and only one DLBCL was present. We registered a Burkitt lymphoma, very rare. Gac et al. published another case in their series in 2009 [23].

Dawson proposed a specific classification for cases with only extranodal disease: Stage I for those affecting only the thyroid gland and Stage II when there is regional node involvement [24] [25]. According Ann-Arbor criteria, nearly 56\% of PTL at diagnosis are stage IE, $32 \%$ at stage IIE, $2 \%$ at stage IIIE and $11 \%$ at stage IVE [26]. 
Half of our patients can be considered in stage IE and half had regional lymph nodes affected.

Ultrasound can show a diffuse gland enlargement. It looks like a heterogeneous hypoechoic parenchyma with the presence of structures resembling septae [27]. In our experience, ultrasonography was not useful to distinguish between lymphoma and subacute thyroiditis in any case.

Despite advances in ultrasonography, as well as in guided core biopsy, accurate diagnosis with an open surgical biopsy is usually needed, especially in MALT subtypes, where no diagnosis can be achieved with FNAC [28]. Some authors [29] recommend FNAC initial analysis with flow cytometry, which achieves a sensitivity of $97 \%$ and a specificity of $87 \%$ for the detection of B-cell lymphoma. However, $13 \%$ of the patients cannot be diagnosed due to inadequate sampling. Moreover, MALT lymphomas require an accurate evaluation of thyroid architecture to distinguish them from benign conditions. In recent years, an increased sensitivity for FNAC has been reported [30] [31]. The addition of other techniques such as flow cytometry or molecular biology may improve the diagnostic rate of FNAC, especially in the differential diagnosis of lymphomas versus carcinomas [32]. BRAF and NRAS determination has been proposed as a marker of PT L [33].

In our series, although all the patients had a previous FNAC, only one patient could be diagnosed by FNAC; the other patients required an open surgical approach. A core-needle biopsy (CNB) yields more tissue than FNAC and it may be guided by ultrasonography to avoid the risk of trauma to adjacent structures. It can facilitate the differential diagnosis with anaplastic carcinoma, which is not always possible with FNAC. Recent studies have shown that a core-biopsy can provide enough tissue for diagnosis in up to $95 \%$ of lymphomas [34]. Ha EJ et al. show that CNB results in diagnostic sensitivity and positive predictive values of $87.5 \%$ and $100 \%$, respectively [35]. A three cohort study published by Hahn Sy et al. showed that CNB has benefit for the diagnosis of thyroid nodules with inconclusive ultrasonography-guided FNA [36].

No CNB was performed in our series due to the lack of experience.

Staging procedures for PTL are essentially the same as other subtypes and includes blood cell analysis, biochemistry including LDH and beta2-microglobulin both important prognostic factors for lymphoma, a bone marrow biopsy and a whole-body CT. An updated diagnosis and response criteria favours the PET/CT use for staging and response evaluation, especially in the aggressive variety, although MALT cases may result in false negative [37]. Galium 67 scintigraphy could have a role in detecting local recurrence [38].

The optimal treatment of PTL is controversial and usually based on histologic subtype. In general, they are sensitive to both chemotherapy and radiotherapy. Due to its more aggressive clinical course, the gold standard for DLBCL is multimodal therapy based on the combination of the monoclonal antibody Rituximab, targeting CD20 antigen with the classical chemotherapy schedule CHOP (cyclophosphamide, doxorubicin, vincristine and prednisone), as well as radiotherapy. In the very aggressive sub- 
types, like Burkitt's lymphoma, a chemotherapy schedule based on Methotrexate, Cyclophosphamide and Cytarabine is the treatment of choice. A systematic review performed by Doria et al, showed relapse rates of $7.7 \%$ following chemo-radiotherapy modality, $37.1 \%$ following radiotherapy alone and $43 \%$ following chemotherapy alone [39].

However, the introduction of Rituximab, a chimeric monoclonal antibody against CD20 represents the most significant advance in the treatment of lymphoma since the introduction of chemotherapy. Adding Rituximab to the therapy has shown to improve overall and disease-free survival in virtually all subtype of B-cell lymphomas and can also reduce $\mathrm{CHOP}$ volume in elderly patients that do not tolerate chemotherapy [40].

Treatment may range from surgery alone, radiotherapy alone, single-agent rituximab or a combination of them. MALT lymphomas may be treated with single-modality treatment because of the indolent course of the disease. Laing et al. reported a series of 31 patients with MALT lymphoma stage I-IIE, who received only surgery followed by single agent rituximab, with a 5-year survival rate of 90\% [41]. Bevacizumab (VEGF inhibitor) has been tested without satisfactory results to date [42].

3 out of our 7 patients in our series were treated with chemoinmunotherapy ( $2 \mathrm{R}-$ CHOP and 1 Methotrexate-based schedules) two with surgery and rituximab and the other two with only surgery. None of them received radiotherapy probably due to the favourable outcome following chemoinmunotherapy.

The role of surgery in the treatment of PTL remains controversial. It allows an accurate histologic diagnosis and avoids the compressive symptoms due to enlarged masses. However, the potential morbidity of the procedure should be kept in mind as well as the fact that surgery does not appear to improve overall survival when compared to other treatment strategies [43] [44]. Despite this, surgery may still be helpful as palliative treatment for critical airway obstruction [45], although the intervention carries high morbidity and could be replaced by corticosteroids as well as chemotherapy [46]. Furthermore, some intrathyroid MALT lymphomas are diagnosed in the setting of total thyroidectomy for another indication. In our centre we performed five open interventions because of compressive symptoms and fast tumor growth in four of them. Some authors suggest surgery as a unique treatment modality for MALT stage IE lymphomas, with a 7 -year survival of $100 \%$ [47]. We could support this evidence based on our experience though it is short and we should see the evolution in a longer period of time.

Radiotherapy should be considered only for localized stage IE MALT lymphomas. In most cases RT is not necessary due to the good results achieved with chemotherapy. It has been used in patients that cannot undergo surgery or chemotherapy, improving local control [48].

Prognosis of PTL is mainly related to histological subtype. The surveillance Epidemiology and End Results database estimates a 5-year disease-free survival of $96 \%$ for MALT lymphoma, 75\% for DLBCL, $87 \%$ for follicular PTL and $86 \%$ for small lymphocytic lymphoma. The 5 -year overall survival was $66 \%$. The outcome is also based on other prognostic factors included in the International Index [49], such as stage, age, 
performance status, more than one extranodal site and elevated LDH.

$100 \%$ of our patients are still alive at a mean follow-up of seven years.

\section{Conclusion}

PTL is very infrequent, so it is difficult to protocolize its diagnosis and treatment. Multimodal treatment gives good results, when histology and stage are taken into account to decide the best combination. Due to the low number of cases, there is no evidence of which is the best treatment option, but experience suggests restricting surgery to cases where previous diagnosis fails. In aggressive histological variants or larger tumors, surgery can be risky and will not improve survival, but for MALT lymphoma confined to the thyroid gland, given their benign presentation and course, if surgery is done, this could work as a single and resolutive treatment.

\section{Conflict of Interest}

Authors state that no conflict of interest exists.

\section{References}

[1] Widder, S. and Pasieka, J.L. (2004) Primary Thyroid Lymphomas. Current Treatment Options in Oncology, 5, 307-313. https://doi.org/10.1007/s11864-004-0021-7

[2] Merino, M.J. and Sidawy, M.K. (1997) The Thyroid Gland. In: Silverberg, S.G., DeLellis, R.A. and Frable, W.J., Eds., Principles and Practice of Surgical Pathology and Citopathology, Churchill Livingstone, New York, 2665-2708.

[3] Katna, R., Shet, T., Sengar, M., Menon, H., Laskar, S., Prabhash, K., et al. (2013) Clinicopathologic Study and Outcome Analysis of Thyroid Lymphomas: Experience from a Tertiary Cancer Center. Head \& Neck, 35, 165-171. https://doi.org/10.1002/hed.22928

[4] Yang, H., Li, J. and Shen, T. (2008) Primary T-Cell Lymphoma of the Thyroid: Case Report and Review of the Literature. Medical Oncology, 25, 462-466.

https://doi.org/10.1007/s12032-008-9059-x

[5] Carbone, P.P., Kaplan, H.S., Musshoff, K., et al. (1971) Report of the Committee on Hodgkin's Disease Staging Classification. Cancer Research, 31, 178-184.

[6] Yeshvanth, S.K., Lakshminarayana, K.H., Upadhyaya, V.S. and Shetty, J.K. (2012) Primary Thyroid Lymphoma Arising from Hashimoto Thyroiditis Diagnosed by Fine Needle Aspiration Cytology. Journal of Cancer Research and Therapeutics, 8, 159-161. https://doi.org/10.4103/0973-1482.95205

[7] Pluot, M. (1999) Que faut-il attendre de la cytoponction? Annales de Chirurgie, 53, 65-68.

[8] Matsuzuka, F., Miyauchi, A., Katayama, S., et al. (1993) Clinical Aspects of Primary Thyroid Lymphoma: Diagnosis and Treatment Based on Our Experience of 119 Cases. Thyroid, 3, 93-99. https://doi.org/10.1089/thy.1993.3.93

[9] Onal, C., Li, Y.X., Miller, R.C., Poortmans, P., Constantinou, N., Weber, D.C., Atasoy, B.M., Igdem, S., Ozsahin, M. and Ozyar, E. (2010) Treatment Results and Prognostic Factors in Primary Thyroid Lymphoma Patients: A Rare Cancer Network Study. Annals of Oncology, 22, 156-164. https://doi.org/10.1093/annonc/mdq310

[10] Graff-Baker, A., Roman, S.A., Thomas, D.C., et al. (2009) Prognosis of Primary Thyroid Lymphoma: Demographic, Clinical, and Pathologic Predictors of Survival in 1408 Cases. Surgery, 146, 1105-1115. https://doi.org/10.1016/j.surg.2009.09.020 
[11] Thomas, R.M. (2012) Hodgkin's Lymphoma Presenting as an Abscess in Thyroid Gland. Indian Journal of Pathology and Microbiology, 55, 122-124. https://doi.org/10.4103/0377-4929.94885

[12] Thieblemont, C., Mayer, A., Dumontet, C., et al. (2002) Primary Thyroid Lymphoma Is a Heterogeneous Disease. Journal of Clinical Endocrinology \& Metabolism, 87, 105-111. https://doi.org/10.1210/jcem.87.1.8156

[13] Wirtzfeld, D.A., Winston, J.S., Hicks, W.L., et al. (2001) Clinical Presentation and Treatment of Non-Hodgkin's Lymphoma of the Thyroid Gland. Annals of Surgical Oncology, 8, 338-341.

[14] Watanabe, N., Noh, J.Y., Narimatsu, H., et al. (2011) Clinicopathological Features of 171 Cases of Primary Thyroid Lymphoma: A Long-Term Study Involving 24553 Patients with Hashimoto's Disease. British Journal of Haematology, 153, 236-243. https://doi.org/10.1111/j.1365-2141.2011.08606.x

[15] Williams, E.D. (1981) Malignant Lymphoma of the Thyroid. Clinics in Endocrinology and Methabolism, 10, 233-394. https://doi.org/10.1016/S0300-595X(81)80018-7

[16] Holm, L., Blomgren, H. and Lowhagen, T. (1985) Cancer Risks in Patients with Chronic Thyroiditis. New England Journal of Medicine, 312, 601-604. https://doi.org/10.1056/NEJM198503073121001

[17] Jennings, A.S. and Saberi, M. (1984) Thyroid Lymphoma in a Patient with Hyperthyroidism. American Journal of Medicine, 76, 551-552. https://doi.org/10.1016/0002-9343(84)90680-6

[18] Yahaya, N., Din, S., Ghazali, M. and Mustafa, S. (2011) Primary Thyroid Lymphoma with Elevated Free Thyroxin Level. Singapore Medical Journal, 52, e173.

[19] Isaacson, P.G. (1999) Mucosa-Associated Lymphoid Tissue Lymphoma. Seminars in Hematology, 36, 139-147.

[20] Isaacson, P.G. (1999) Gastrointestinal Lymphomas of T- and B-Cell Types. Modern Pathology, 12, 151-158.

[21] De Melo, G., Sguilar, D., Petiti, C., Eichstaedt, A., Caiado, R. and de Souza e Souza, R. (2010) Concomitant Thyroid Malt Lymphoma and Papillary Thyroid Carcinoma.. Arquivos Brasileiros de Endocrinologia \& Metabologia, 54, 425-428. https://doi.org/10.1590/s0004-27302010000400013

[22] Cakir, M., Celik, E., Tuncer, F. and Tekin, A. (2013) A Rare Coexistence of Thyroid Lymphoma with Papillary Thyroid Carcinoma. Annals of African Medicine, 12, 188-190. https://doi.org/10.4103/1596-3519.117632

[23] Gac, P., Cabané, P., Amat, J., Zamorano, R., Pineda, P., Morales, C., Valenzuela, C. and Rodríguez, F. (2009) Primary Thyroid Lymphoma. Report of Four Cases. Revista Médica de Chile, 137, 928-935.

[24] Dawson, I.M., Cornes, J.S. and Morson, B.C. (1961) Primary Malignant Lymphoid Tumors of the Intestinal Tract. Report of 37 Cases with a Study of Factors Influencing Prognosis. British Journal of Surgery, 49, 80-89. https://doi.org/10.1002/bjs.18004921319

[25] Ruggiero, F.P., Frauenhoffer, E., Stack, B. (2005) Thyroid Lymphoma: A Single Institution's Experience. Otolaryngology_Head and Neck Surgery, 133, 888-896. https://doi.org/10.1016/j.otohns.2005.07.040

[26] Graff-Baker, A., Roman, S.A., Thomas, D.C., Udelsman, R. and Sosa, J. (2009) Prognosis of Primary Thyroid Lymphoma: Demographic, Clinical, and Pathologic Predictors of Survival in 1,408 Cases. Surgery, 146, 1105-1115. https://doi.org/10.1016/j.surg.2009.09.020

[27] Nam, M., Shin, J.H., Han, B.K., et al. (2012) Thyroid Lymphoma: Correlation of Radiologic 
and Pathologic Features. Journal of Ultrasound in Medicine, 31, 589-594.

[28] Swart, G.J., Wright, C., Brundyn, K., Mansvelt, E., du Plessis, M., ten Oever, D., et al. (2007) Fine Needle Aspiration Biopsy and Flow Cytometry in the Diagnosis of Lymphoma. Transfusion and Apheresis Science, 37, 71-79. https://doi.org/10.1016/j.transci.2007.06.001

[29] Cha, C., Chen, H., Westra, W.H. and Udelsman, R. (2002) Primary Thyroid Lymphoma: Can the Diagnosis Be Made Solely by Fine-Needle Aspiration? Annals of Surgical Oncolo$g y$, 9, 298-302. https://doi.org/10.1007/BF02573069

[30] Kwak, J.Y., Kim, E.K., Ko, K.H., et al. (2007) Primary Thyroid Lymphoma: Role of Ultra-Sound-Guided Needle Biopsy. Journal of Ultrasound in Medicine, 26, 1761-1765.

[31] Dustin, S.M., Jo, V.Y., Hanley, K.Z. and Stelow, E. (2012) High Sensitivity and Positive Predictive Value of Fine-Needle Aspiration for Uncommon Thyroid Malignancies. Diagnostic Cytopatholog, 40, 416-421. https://doi.org/10.1002/dc.21802

[32] Daneshbod, Y., Omidvari, S., Daneshbod, K., Negahban, S. and Dehghani, M. (2006) Diffuse Large B Cell Lymphoma of Thyroid as a Masquerader of Anaplastic Carcinoma of Thyroid, Diagnosed by FNA: A Case Report. CytoJournal, 3, 23. https://doi.org/10.1186/1742-6413-3-23

[33] Aggarwal, N., Swerdlow, S.H., Kelly, L.M., Ogilvie, J.B., Nikiforova, M.N., Sathanoori, M. and Nikiforov, Y.E. (2012) Thyroid Carcinoma-Associated Genetic Mutations Also Occur in Thyroid Lymphomas. Modern Pathology, 25, 1203-1211.

https://doi.org/10.1038/modpathol.2012.73

[34] Demharter, J., Muller, P., Wagner, T., Haude, K. and Bohndorf, K. (2001) Percutaneous Core-Needle Biopsy of Enlarged Lymph Nodes in the Diagnosis and Subclassification of Malignant Lymphomas. European Radiology, 11, 276-283.

https://doi.org/10.1007/s003300000540

[35] Ha, E.J., Baek, J.H., Lee, J.H., Kim, J.K., Song, D.E., Kim, W.B. and Hong, S.J. (2015) Core Needle Biopsy Could Reduce Diagnostic Surgery in Patients with Anaplastic Thyroid Cancer or Thyroid Lymphoma. European Radiology, 26, 1031-1036. https://doi.org/10.1007/s00330-015-3921-y

[36] Hahn, S., Shin, J., Han, B., Ko, E. and Ko, E. (2013) Ultrasonography-Guided Core Needle Biopsy for the Thyroid Nodule: Does the Procedure Hold Any Benefit for the Diagnosis When Fine-Needle Aspiration Cytology Analysis Shows Inconclusive Results? British Journal of Radiology, 86, Article ID: 20130007. https://doi.org/10.1259/bjr.20130007

[37] Takalkar, A., El-Haddad, G. and Lilien, D.L. (2008) FDG-PET and PET/CT-Part II. The Indian Journal of Radiology \& Imaging, 18, 17-36. https://doi.org/10.4103/0971-3026.38504

[38] Nishiyama, Y., Yamamoto, Y., Yokoe, K., Satoh, K. and Ohkawa, M. (2003) Diagnosis of Thyroid Lymphoma and Follow-Up Using Ga-67 Scintigraphy. Annals of Nuclear Medicine, 17, 351-357. https://doi.org/10.1007/BF03006600

[39] Doria, R., Jekel, J.F. and Cooper, D.L. (1994) Thyroid Lymphoma. The Case for Combined Modality Therapy. Cancer, 73, 200-206. https://doi.org/10.1002/1097-0142(19940101)73:1<200::AID-CNCR2820730135>3.0.CO;2-\#

[40] Kahara, T., Iwaki, N.N., Kaya, H., Kurokawa, T., Yshida, T., Ishikura, K. and Usuda, R. (2010) Transition of Thyroid Autoantibodies by Rituximab Treatment for Thyroid MALT Lymphoma. Endocrine Journal, 58, 7-12. https://doi.org/10.1507/endocrj.K10E-166

[41] Laing, R.W., Hoskin, P., Hudson, B.V., et al. (1994) The Significance of MALT Histology in Thyroid Lymphoma: A Review of Patients from the BNLI and Royal Marsden Hospital. Clinical Oncology, 6, 300-304. https://doi.org/10.1016/S0936-6555(05)80271-7

[42] Stopeck, A.T., Unger, J.M., Rimsza, L.M., et al. (2012) A Phase 2 Trial of Standard-Dose 
Cyclophosphamide, Doxorubicin, Vincristine, Prednisone (CHOP) and Rituximab plus Bevacizumab for Patients with Newly Diagnosed Diffuse Large B-Cell Non-Hodgkin Lymphoma: SWOG 0515. Blood, 120, 1210-1217.

https://doi.org/10.1182/blood-2012-04-423079

[43] Pyke, C.M., Grant, C.S., Habermann, T.M., et al. (1992) Non-Hodgkin's Lymphoma of the Thyroid: Is More than Biopsy Necessary? World Journal of Surgery, 16, 604-609. https://doi.org/10.1007/BF02067333

[44] Friedberg, M.H., Coburn, M.C. and Monchik, J.M. (1994) Role of Surgery in Stage IE Non-Hodgkin's Lymphoma of the Thyroid. Surgery, 116, 1061-1067.

[45] Sippel, R.S., Gauger, P.G., Angelos, P., et al. (2002) Palliative Thyroidectomy for Malignant Lymphoma of the Thyroid. Annals of Surgical Oncology, 9, 907-911. https://doi.org/10.1007/BF02557529

[46] Myatt, H.M. (1996) Acute Airway Obstruction Due to Primary Thyroid Lymphoma. Revue de Laryngologie Otologie Rhinologi, 117, 237-239.

[47] Derringer, G.A., Thompson, L.D., Frommelt, R.A., et al. (2000) Malignant Lymphoma of the Thyroid Gland: A Clinicopathologic Study of 108 Cases. American Journal of Surgical Pathology, 24, 623-639. https://doi.org/10.1097/00000478-200005000-00001

[48] Harrington, K.J., Michalaki, V.J., Vini, L., et al. (2005) Management of Non-Hodgkin's Lymphoma of the Thyroid: The Royal Marsden Hospital Experience. British Journal of Radiology, 78, 405-410. https://doi.org/10.1259/bjr/31803121

[49] The International Non-Hodgkin's Lymphoma Prognostic Factors Project (1993) A Predictive Model for Aggressive Non-Hodgkin's Lymphoma. New England Journal of Medicine, 329, 987-994. https://doi.org/10.1056/NEJM199309303291402

\section{Submit or recommend next manuscript to SCIRP and we will provide best service} for you:

Accepting pre-submission inquiries through Email, Facebook, LinkedIn, Twitter, etc.

A wide selection of journals (inclusive of 9 subjects, more than 200 journals)

Providing 24-hour high-quality service

User-friendly online submission system

Fair and swift peer-review system

Efficient typesetting and proofreading procedure

Display of the result of downloads and visits, as well as the number of cited articles

Maximum dissemination of your research work

Submit your manuscript at: http://papersubmission.scirp.org/

Or contact jct@scirp.org 